\title{
Musical motivation: Towards a model synthesising the research
}

Dr Susan Hallam, Institute of Education, University of London, 20 Bedford Way, London,

\section{WC1H OAL.}

E-mail shallam@globalnet.co.uk

Susan Hallam trained as a violinist at the Royal Academy of Music after which she spent 10 years as a full time professional musician. An interest in psychology led her to take a BA in Psychology externally with London University. This was followed by a career in teaching, culminating in the post of Head of Upper Strings for Oxfordshire Local Education Authority. Her PhD studies, relating to the development of expertise in musicians, were completed at the Institute of Education, London University where she became a lecturer in 1991. She later became Senior Lecturer in the Psychology of Education and Assistant to the Dean of Professional Development. In 1999 she was appointed as Professor in Education at Oxford Brookes University returning to the Institute of Education in London in 2001. She has published widely in areas as diverse as attendance at and exclusion from school, ability grouping, homework, and teaching and learning in secondary, further and higher education. Her work in music has two main strands: learning and performance in music and the effects of music on learning and behaviour. In addition to her personal research, she has undertaken funded research for the Department for Employment and Education on Instrumental Music Services and assisted the Qualifications and Curriculum Authority in mapping the provision of examinations in music and related areas. Her most recent book is Instrumental teaching: A practical guide to better teaching and learning published by Heinemann. 


\title{
Musical motivation: Towards a model synthesising the research
}

\begin{abstract}
This article explores motivation to participate in music making activities. It examines historical and current theories of motivation and sets out a model describing the way that the characteristics of the individual including, personality, self-concept and personal goals interact with the environment to influence motivation and subsequent behaviour. The environment may include culture and sub-cultures, society, time, place, institutions, family and peers and the rewards and punishments that these offer. The article then explores research relating to motivation to actively participate in music. This supports the notion that musical motivation is determined by complex interactions between the individual and the environment within which they find themselves. The article concludes with a consideration of directions for future research.
\end{abstract}




\section{Musical motivation: Towards a model synthesising the research}

\section{Theories of motivation}

\section{The historical perspective}

The study of human motivation has a long history. Theorists have attempted to explain it from a wide range of different perspectives. These fall into three main groupings, those which emphasise motivation as deriving from within the individual, those where the individual is perceived to be motivated by environmental factors and those where motivation is seen as a complex interaction between the individual and the environment mediated by cognition. Early theories saw motivation as deriving from the needs of the individual to satisfy the basic requirements for survival, e.g. food, drink. These theories suggested that motivation was based on drive reduction. When basic needs were satisfied motivation waned (Hull, 1943). Motivation in the modern world was viewed as an extension of these biological needs which were mediated through the need to work to earn money to pay for food, shelter, etc. Behaviourists, taking an environmentalist position, viewed motivation as being driven primarily by drives such as hunger but also by external forces such as rewards and punishments (Thorndike, 1913; Skinner, 1950). Behaviour which was positively rewarded was likely to be repeated, that which led to punishment was likely to be avoided.

Psychoanalytic theories, as exemplified by the work of Freud, explained behaviour in terms of the human being as an energy system, driven by sexual and aggressive drives and operating in the pursuit of pleasure (tension reduction). Motivation was viewed as the way the individual pursued these drives or their more acceptable alternatives (Freud, 1949; 1960). More recent psychoanalytic theories have moved away from viewing motivation as underpinned by sexual 
drives and have stressed the tendency of the individual towards growth and self-development. The work of later theorists such as Erikson $(1950,1959)$ and Horney (1950) acknowledged the role of the environment in the development of motives and the importance of parenting in this process.

Trait and type theories of personality viewed motivation as relating to a set of personality traits (Allport, 1937; Murray, 1938; Cattell, 1957; Eysenck, 1982) embedded, to some extent, within human biology (Buss, 1989). Evidence that newborns exhibit markedly different temperaments supports this view (Kagan and Snidman, 1991). Recent trait theories, based on computer analysis of large data sets, suggest 5 main traits: neuroticism, extraversion, openness, agreeableness and conscientiousness each implicitly related to different motivational characteristics (Macrae and Costa, 1987).

Humanistic theories emphasised the individual's uniqueness and freedom to choose a particular course of action (Rogers, 1961; Maslow, 1954). Motivation was viewed as a striving towards self-fulfilment through self-actualisation, maturity and socialization. Self-actualisation explains human creativity, our constant attempts to improve and change and our attempts to maintain and enhance our self-esteem. These self-developments are influenced strongly by environmental factors in the form of feedback given by others.

Modern theories of motivation have evolved from these major meta-theoretical positions taking much greater account of cognition, the way our perceptions of events are determined by our construction of them, and the ways in which our interpretations of them subsequently influence the constantly changing perceptions we hold of ourselves. They acknowledge the capacity of the 
individual to determine their own behaviour, whilst also recognising the role of the environment in rewarding or punishing particular behaviours which then influences thinking and subsequent actions. A further key issue for understanding motivation, which modern theories have begun to address is the way that motivation operates at different levels and time scales. At the highest levels, motivation to behave in particular ways may be determined by needs deriving from the individual's personality and goals which are specified over the life span. In the medium term, behaviour may be determined by the need to achieve intermediate goals, while maintaining selfesteem. Actual behaviour at any single point in time, while it may be influenced by longer term goals, will also depend on decisions made between competing motivations and needs and 'coping' with the demands of the environment.

\section{Personality, cognition and motivation}

All modern theories of motivation take account of cognition - an acceptance that much of our behaviour is mediated by our thoughts about and perceptions of events. Personal Construct Theory (Kelly, 1955) suggests that our behaviour is not so much affected by our actual experiences but by how we perceive and interpret them. Kelly viewed man as a scientist, observing the world, devising hypotheses, testing them, and revising them when they were unworkable. He suggested that people create meaning for themselves and through the concepts that they acquire make sense of their world and become able to predict and understand the things that happen to them. These interpretations affect future behaviour.

This process is influenced, in part, by the extent to which the individual perceives that $\mathrm{s} / \mathrm{he}$ has control over situations. The concept, locus of control, first proposed by Rotter (1966), suggests that some individuals perceive that they are in control of their lives (internal locus of control) while others believe that they are controlled by external forces (external locus). 
Some researchers have suggested that individuals' personalities make them more or less likely to be motivated intrinsically or extrinsically. The intrinsically motivated individual has been described as an 'origin' (De Charms, 1968). Origins see themselves as the cause of their own behaviour, in charge of their lives and having ownership of what they are and what they do. Individuals who see themselves as being directed by others or at the mercy of external events are known as 'pawns'. They do what they believe others have decided for them, have little sense of ownership, have an external locus of control and are not easily motivated intrinsically (De Charms, 1968). Closely related is 'learned helplessness' where learners believe that there is nothing that they can do to improve their situation (Seligman and Maier, 1967). Exploring people's styles of explaining what happens to them, Seligman and colleagues suggested that a pessimistic style predicted depression while an optimistic one promoted good physical and mental health (Seligman and Nolen-Hoeksema, 1987).

Another research tradition has emphasised the ways in which people think about themselves and their relationships with others and how from this, the self-concept develops and is represented in our thinking (Sullivan, 1964; Rogers, 1961; Mead, 1934). Modern selftheories, developed from these underpinnings, have explored the concept of the interpersonal self (Markus and Oyserman, 1989) allowing an understanding of a wide variety of cultural and gender differences in the extent to which others are included in the self, while Baldwin and Holmes (1987) provide an explanation of how the self-other dividing line can be bridged through peoples dialogues with 'private audiences', i.e. how by internalising others they can through internal dialogue serve a pivotal role in self-regulation These theoretical ideas, taken together, have been influential in the development of current 
social cognitive theories of motivation which have attempted to integrate personality, the self and motivation. Mischel (1973) set out the key socio-cognitive variables, the individual's interpretation of situations and events; their expectations; and the goals that they have that mediate and regulate behaviour. Considerable research has been undertaken within this broad framework.

\section{Motivation and purpose}

Historically, many theorists taking different perspectives, have stressed that research should focus on what people are trying to do, not what they actually do (Murray, 1938; Allport, 1937; Adler, 1927; Erikson, 1950). There have been two main strands to this research, one focussing on satisfying needs and the other on setting goals. Murray (1938) suggested that some motives were basic to human functioning and that people possessed them to different degrees. He arrived at a list of 20 motives which were seen as drive like forces shaped by experience. Four received extensive research attention, needs for achievement, power, affiliation and self-determination. In education, need for achievement has been the most extensively considered. This refers to a perceived need in some individuals to be more successful and better than others (McClelland et al., 1953; Atkinson, 1964). Need for achievement is based on two complementary elements, the motive to achieve success, which enhances the ego, and the motive to avoid failure, which involves the fear of losing face. For some high need achievers, gaining success is a stronger motive than avoiding failure. For them the greatest enhancement to their ego occurs when the chances of succeeding are evenly balanced with the chances of failing. Low-need achievers are motivated by the avoidance of 
failure. For them the most attractive situations are those where success is certain, or almost so or so unlikely that they will not lose face if they do not succeed. Need for achievement has not proved successful in predicting performance in school, probably because it can be fulfilled in non-academic ways but it is an important motivator for some learners (Entwisle, 1972).

Related to this, Koestner and McClelland (1990) suggest a conception of human motivation as a need for competence. This, derived from the work of White (1959) and drawing on the theories of Murray (1938), Lewin (1951) and Maslow (1954), is based on a view of humans as proactive organisms who are motivated to extend their capabilities and to interact with their environment effectively, i.e. a need for competence. Intrinsic motivation is based in these innate, organismic needs for competence and self-determination (Deci and Ryan, 1985), which provide the impetus for a process of seeking out and attempting to master particular challenges. Extrinsic motivation occurs when a task is undertaken for external reward. If a task is optimally challenging it should generate intrinsic motivation because it provides the individual with the greatest opportunity to stretch his or her capacities. Tasks that are intrinsically motivating share certain structural and emotional characteristics (Csikszentmihalyi, 1990) offering a level of challenge that is in balance with a person's current skills (Good and Brophy, 1991). When this occurs an individual derives pleasure from the work and tends to continue with it. This is known as a state of flow. If the task is too easy the person becomes bored. If the work demands skills beyond the capabilities of the individual anxiety is created. The activities which continue to be pursued to satisfy competence needs depend on the feedback the individual receives from the environment. The way that individuals perceive and interpret this feedback will be considered later. 
A more recent approach to studying human purpose has been through the goals which people set themselves. Several theories have developed. They are middle level explanatory units which take account of both context and cognition. One example is 'possible selves'. If an individual perceives him or herself as successful and attributes this success to high ability they may come to include in their self-concept a 'positive possible future self' in that domain (Markus and Ruvolo, 1989). Possible selves can be powerful motivators, which provide long term goals to aim for. They encourage the setting up of interim goals which need to be achieved en route to the long term goal. Where individuals do not view themselves as having a possible self in a particular domain in the short or long term their motivation is likely to be less. A similar formulation is the proposal that individuals develop self-narratives about their lives - stories that they tell to define who they are, have been and who they may be in the future (McAdams, 1988). Schlenker proposes self-identifications which are fine tuned to meet the demands and realities of different social audiences. Individuals construct and negotiate many sets of 'desired identity images' that guide their behaviour in different contexts (Schlenker and Weigold, 1989). These theories outline how the individual can take a creative perspective of themselves over time and revise and set up new goals as they determine their future direction.

In addition to research on the way that conceptions of the self can become dynamic motivators, other theorists have developed conceptualisations of how individuals move towards their desired selves. For example, Emmons (1989) describes 'personal strivings' what the person is trying to achieve in a variety of ways in many different life settings and for relatively long periods of time. Other conceptualisations include 'personal projects' (Little, 
1989); 'life tasks' (Cantor and Kihlstrom, 1985,1987); and 'current concerns' (Klinger,

$(1975,1977 ; 1987)$. What they have in common is that they emphasise the individuals' capacity to choose life activities and pre-occupations and to express their intentions in action.

Recent research has demonstrated possible links between needs based achievement and competence motivation and goal orientation (Elliot, 1997). Elliot suggests that achievement motives are the underlying personality factors that orient people towards different achievement goals. He has shown how achievement motive measures can be used to predict achievement goal orientation.

\section{Goals in education}

In education, particular goal orientations have been explored, performance and learning (Diener and Dweck, 1978; 1980; Dweck and Elliott, 1983; Elliott and Dweck, 1988). Performance goals are concerned with gaining positive judgements of competence and avoiding negative ones. In contrast, learning goals are concerned with increasing mastery, reflecting the desire to learn new skills, master new tasks or understand new things. Several studies have manipulated students' goals and beliefs about their likelihood of success and have found that those adopting performance goals are more vulnerable to developing helpless responses (Elliott and Dweck, 1988), particularly when they are focussed on the possibility of failure (Elliot and Church, 1997). Dweck (1975) described how some students believed that once failure had occurred the situation was out of their control and nothing could be done. Having failed on a task, these students denigrated their intelligence, their expectations plummeted and they experienced negative emotions, lower persistence and deteriorating performance. In contrast, those students who adopt 
a learning goal orientation tend to use deeper more effective learning strategies and apply what they have learned more effectively (Ames and Archer, 1988; Pintrich and Garcia, 1994). There is also a relationship between students' theories of intelligence and their goal choices. Where students hold an entity theory of intelligence (fixed and immutable) they are more likely to adopt performance goals while those holding an incremental view of intelligence are more likely to choose a learning goal (Dweck and Leggett, 1988). Exploring the relationships between entity and incremental theories of intelligence, confidence, reactions to failure and school grades, Henderson and Dweck (1990) and Sorich and Dweck (2000) found that students who had a fixed view of intelligence performed less well than those with an incremental view even when the latter had low confidence in their ability. Those with entity theories also tended to minimise the amount of time they put into their school work (Maehr and Midgely, 1996) and believed that if they did not have sufficient ability, hard work would not compensate (Stipek and Gralinski, 1996). They believed that being good at something meant that it was not necessary to work at it (Mueller and Dweck, 1998). Some students have been shown to deliberately make no effort on difficult tasks to protect their beliefs about their ability. This is known as self-handicapping (Berglas and Jones, 1978).

\section{Perception, interpretation and self-regulation}

The theoretical positions outlined above stress the importance of cognition in the regulation of our behaviour. They indicate that higher level goals can mediate our responses to environmental feedback. For instance, envisioning positive possible selves may provide the motivation for us to persist when tasks are difficult (Markus and Ruvolo, 1989), imagining a private audience that offers unconditional approval after sub-optimal task performance may 
protect against self-blame (Baldwin \& Holmes, 1987); simulating worse case scenarios may serve as protection and energise performance in high risk tasks for some pessimists (Norem and Cantor, 1986); and holding particular views of intelligence may affect our goals and subsequent performance (Dweck, 1999).

The self-regulation of goals and behaviour comprises the cognitive - affective work that an individual undertakes to anticipate and prepare for action to monitor behaviour as it unfolds and to look back on outcomes and initiate corrective responses (Cantor and Zirkel, 1990). Individuals, while maintaining higher level goals, may in particular situations behave in a manner that appears contrary to them if the situation appears to demand it or there are other competing goals (Vallacher and Wegner, 1987). They may have to make trade offs between goals at different levels.

\section{Attribution theory}

An important influence on motivation, is how we attribute our successes and failures

(Weiner, 1986). The causes of success or failure can be seen as stable or unstable; controllable or uncontrollable and internal or external. If we attribute failure to something which is unstable, e.g. bad luck, which may not occur in the future, expectations about future performance are likely to be unaffected. However, if failure is attributed to a stable factor, e.g. lack of ability, then there will be an expectation of continued failure (Weiner, 1986). Some causes are perceived to be within our control, e.g. the effort we make, while others, e.g. the difficulty of the test, are not. Some are internal, e.g. intellectual capabilities, others are not, e.g. the quality of the teaching we receive. In explaining success and failure these three 
elements interact with each other. More recently, an alternative approach to attribution has been identified, strategy attributions (Clifford, 1986). Here failure is explained by a lack of specific strategies or skills rather than effort or general ability.

While attributions relate to individual performance on specific tasks, reviews of the literature have identified some common features (Bar-Tal, 1978). Females tend to attribute their success to luck rather than to ability; individuals with low self-esteem tend to make internal attributions (low ability) following failure; high need achievers tend to attribute their success to internal factors, ability and effort, to which greatest pride is attached and their failures either to external factors, or to lack of effort. Low need achievers attribute their failure to lack of ability and their success to luck or the fact that the task was easy (Bar-Tal, 1978). There are also cultural differences. In Eastern cultures there is a tendency to attribute success to factors which are controllable and modifiable, particularly effort (Hau and Salili, 1990). In Western cultures, students tend to adopt ability attributions (Holloway, 1988), although this is not always the case (Dweck, 1999).

\section{Self efficacy}

As we have seen, a number of theorists have included the expectancy of future outcomes as providing the motivational reinforcement for behaviour (Rotter, 1966; Mischel, 1973; Bandura, 1977). The central proposition of these approaches is that the regulation of behaviour is guided by self-imposed goals and the consequences that ensue from them. Bandura assigns a role to efficacy beliefs in determining whether particular goals will be pursued and subsequently achieved (Bandura, 1977; 1982). When people approach a task they form expectations about how well they think they will be able to carry out that particular task. Such expectations will be based 
on their previous performance. This is known as self-efficacy (Bandura, 1977). Beliefs about selfefficacy are tied to particular tasks and depend on how we explain to ourselves our previous successes and failures.

Bandura's theory suggests that motivation for an activity will be at its peak when strong selfefficacy beliefs are combined with some moderate uncertainty about the outcome, i.e. when a person feels competent but challenged (Bandura, 1989). Cognitive evaluation theory goes further suggesting that feelings of self-determination are a necessary condition for intrinsic motivation to flourish. So even if an activity is challenging and a person feels themselves to be highly competent they will not display high levels of intrinsic motivation unless the activity is perceived as self-determined (Deci and Ryan, 1980). Both theories suggest that competence feedback plays an important role in motivation. However, the interpretation of feedback may be affected by gender. Males tend to view praise as affirming their competence at the activity which translates into heightened intrinsic motivation, females tend to interpret praise as meaning that they are being controlled (Deci and Ryan, 1985), although the way that the feedback is delivered may be important. Where it is clearly either controlling or not, there are no gender differences (Ryan, 1982). Locus of control is also important. Children with internal locus of control respond more favourably to praise than children with an external locus of control (Danner and Lonky, 1981).

There is also some evidence that confidence in ones ability does not necessarily facilitate motivation when students are faced with failure. High confidence students with performance goals did worse when they met difficulties than those with lower confidence and mastery goals (Henderson and Dweck, 1990, Dweck, 1999). Students with records of success and high 
levels of confidence are often the most vulnerable when they meet failure. There also seem to be gender differences. A series of studies have found that intelligent girls tend to avoid challenge and when faced with difficulties readily blame their lack of ability and fall into a helpless pattern (Licht and Dweck, 1984).

\section{Expectancy value models}

Expectancy - value models focus on motivation more specifically at the level of particular tasks (e.g. Eccles, 1983; Feather, 1982). Such models have three main components: value components - students' beliefs about the importance and value of the task(s); expectancy components students' beliefs about their ability or skill to perform the task; and affective components students' feelings about themselves or their emotional reactions to the task.

Value components incorporate three elements: the individual's perception of the importance of the task; the intrinsic value of or interest in the task; and the utility of the task for future goals (Eccles, 1983). In relation to the intrinsic - extrinsic distinction, several theorists have suggested that students may be more oriented towards either intrinsic or extrinsic goals (Harter, 1981); learning or performance goals (Dweck and Elliott, 1983); task-involved versus ego-involved orientations (Nicholls, 1984); or have deep or surface approaches to learning (Marton and Saljo, 1976; Entwistle, 1988; Biggs, 1987a, 1987b). Generally, most people are motivated by complex combinations of motives, intrinsic and extrinsic (Harter 1985; Connell, 1985; Pintrich 1989). While there is some evidence that giving rewards for tasks that are normally undertaken anyway can reduce intrinsic motivation, not all the evidence supports this (Deci, 1971; Calder and Straw, 1975). The relationships almost 
certainly depend on the nature of the task. If it has natural rewards or the reward is unexpected, payment can greatly increase enjoyment (Lepper et al. 1973). In real life situations humans are constantly rewarded for the same activities intrinsically and extrinsically. Where external reward is seen as indicating competence in a worthwhile task it is likely to encourage intrinsic motivation. This allows the individual to continue to value the task as his or her personal area of competence. Reward that is seen as externally imposed to control behaviour on an otherwise unvalued activity is likely to lead to the learner doing what is required and no more.

Expectancy components relate to students' beliefs about their ability to perform a task, their judgments of self-efficacy and control and their expectancy for success. Self-efficacy, as described above, is distinct from expectancy for success as the latter may take account of a range of factors including the effort the student is prepared to make, having sufficient time, etc. All expectancy models propose that perception of internal control results in positive outcomes. However, the evidence is mixed (Pintrich, 1989). A high level of control can be debilitating when a student fails at a task. Harter (1985) proposes that what is important is beneffectance. This involves the individuals tendency to attribute successful outcomes to internal causes and unsuccessful to external. Individuals with high levels of beneffectance tend to perform better on academic tasks.

Affective components relate to anxiety regarding performance, e.g. the taking of tests (Pintrich, 1989) and the need for individuals to maintain self-esteem and self-worth. Covington (1984) suggests that because individuals are motivated to establish, maintain and promote a positive self-image, they may develop a variety of coping strategies to maintain self-worth some of which 
may be self-defeating, for instance, reducing effort. Students who try harder increase the probability of their success but also increase the risk of having to make an attribution for failure followed by a drop in expectancy for success and self-worth if they are not successful (Covington, 1984).

\section{Towards a model of motivation in music}

As can be seen from the brief review of the literature on theories of motivation outlined above, the study of motivation is extremely complex and needs to take account of many different and inter-related factors. Figure 1 provides a framework for enabling us to understand some of these complex interactions which may be applied within a musical context. Our personality, self-concept and self-esteem are, in part, determined by feedback from the environment. We are motivated because we desire social approval, particularly from those we admire and respect. Such praise is internalised, raises self-esteem, and enhances confidence. Individuals set themselves goals, which determine their behaviour. These goals are influenced by personality, ideal and possible selves as well as environmental factors. Behaviour is the end link in the chain but at the time of enactment it too can be influenced and changed by environmental factors. There is interaction between the environment and the individual at every level and in the long and short term. Individuals can act upon the environment to change it, or seek out new environments more conducive to their needs.

\section{Figure 1 near here}


The model recognises the importance of cognitive factors and self-determination in behaviour. While we have needs and desires we are aware that we need to consider the consequences of our actions before we attempt to satisfy them. Cognition plays a role in the ways in which we attempt to enhance our self-esteem leading us to attribute our success or failure to causes which will allow us to maintain a consistent view of ourselves. When a learner has completed a learning task successfully this will have an impact on self-esteem and motivation which will be carried forward to subsequent learning tasks. Conversely, when learning outcomes are negative, motivation is usually impaired.

\section{Motivation in music}

Much of the research on motivation in music has not been embedded within motivational research paradigms or theoretical positions. Psychological research exploring musical motivation has been almost exclusively concerned with motivation to learn and continue to play an instrument. There has been little interest in motivation to listen to music. This focus reflects recent psychological interest in the development of expertise and the factors which affect it and the tendency for learning to play an instrument to be a voluntary activity which allows freedom of choice in starting and continuing to play. Motivation is also of interest because of its link with practice which is seen to be an important determinant of the level of expertise attained in music (for a review see Hallam, 1997). So what factors may be important in determining motivation to begin and continue learning to play an instrument? As outlined in Figure 1, the extent to which an individual is motivated to pursue musical activity will depend on the interactions between their characteristics, self concept and goals and the characteristics of the immediate environment, 
including cultural and historical factors, the educational environment and the support they receive from family and peers.

\section{Environmental factors}

Music is not valued equally in all cultures. In some it is viewed as decadent and is forbidden. In others it is highly valued and those involved in its composition or execution are highly revered members of society. Within any particular culture different types of music may be differentially valued, different groups within society may value different types of music and the value placed on music may change over time. In some places and at some times the environment is very conducive to musical activity, e.g. New Orleans in the time of Louis Armstrong, Europe in the 18th and 19th centuries. Economic, demographic and political factors can also have a major impact on the musical opportunities that may be available (Simonton, 1997). We know very little about how these cultural and societal factors mediate motivation to play and continue to play a musical instrument or how they affect which instrument is chosen to be played. In the Western world some individuals learn because it is expected of them by their parents or school. Others start by chance because tuition is on offer in school and their friends have decided to play. A few may be genuinely inspired by hearing or seeing a famous performer playing a particular instrument, others have a general interest in music and wish to pursue this further. Recently, there is evidence that an increasing number of adults are learning to play an instrument (ABRSM, 1997). Exploring their reasons for so doing would provide valuable insights into musical motivation.

Although, most individuals are involved in full time education when they take up a musical 
instrument, there has been almost no research on the relationship between the institutional learning environment and motivation to engage with music. While some institutions are known to encourage interest in particular domains, e.g. music, sport, there has been no empirical study of how this might affect individual motivation. There is evidence that there are relationships between institutional and departmental expectations and the amount of time spent practising (Jorgensen, 1997). These appear to be further mediated by the dominating value system within the institution which suggests that institutional ethos may be an important factor influencing individual motivation. This is supported by recent research on instrumental music services in the UK where teachers reported that the support of the head teacher and class music teacher were crucial in the extent to which their instrumental teaching could be effective in a school (Hallam and Prince, 2000).

There has been more research on the role of the teacher in promoting motivation. The influence of early teachers, who are viewed as warm and sympathetic seems to be particularly important (Sosniak, 1985; Sloboda and Howe, 1991). Perhaps, in the early stages of learning to play an instrument relatively uncritical encouragement is required. Later, teachers who provide high status role models may enhance motivation (Manturzewska, 1990). Studies of teachers' encouragement of practice have suggested that negotiating individual practising contracts (Wolfe, 1987) and asking students to keep written practice reports (Wagner, 1975) can be effective. However, Rubin-Rabson (1941) found that extrinsic rewards and verbal encouragement were not necessarily effective ways to motivate students to practise while Hallam (1983) found that the support of teachers and parents was important for encouraging practice in girls but that boys tended to be more influenced by their peers. Overall, the most important attitudinal predictor of practising was the individual's own self-determination. 
The role of the family has been the focus of much research related to the development of musical expertise. In the early years the family are likely to be the main source of musical stimulation and may be crucial in engendering future interest in music. We know that responses to music occur in the womb (Lecaunet, 1996); newborn infants and those of a few days old are soothed and attentive to music which their mothers have listened to on a daily basis during pregnancy (Hepper, 1988); and babies show a preference for listening to music that their mother has sung while they were in the womb (Satt, 1984). The age at which children first sing is related to the number of musical behaviours initiated by the parents (Howe et al., 1995) and the development of perfect pitch seems to occur with particularly systematic exposure to music in early childhood (Sergeant, 1969). In providing early opportunities for pleasing interactions with music parents are likely to develop motivation for further involvement in music in their children. Later, parents may play a role in identifying potential in their child and selecting the instrument to be played.

Family support has been demonstrated to be important in promoting the development of high levels of musical skill (for a review see Hallam, 1997). Having musical parents or a musical home environment may influence participation in music (Leblanc corporation, 1961), although active parental involvement is not always a significant predictor of musical achievement. What seems important is the practical help that the family provides in taking pupils to concerts, providing resources, etc. (Zdzinski, 1991). In some cases, the child's taking up an instrument develops parental interest in music (Davidson et al, 1996).

High musical achievers often have parents who have very high expectations of them and are demanding in those expectations (Bastian, 1989; Lassiter, 1981). The child seems to internalise 
these and achievement becomes a need in itself. However, we do not know what happens to children whose parents have high expectations which are unmet. These children may develop low self-esteem and ultimately give up playing.

One important function of the family may be motivating children to practise. Few children appear to be totally self-motivated to practise and the parents of those achieving at a high level tend to support practice, either by encouragement or supervision, although in some cases this may be limited to checking the length of time spent practising (Sosniak, 1985; Sloboda and Howe, 1991; Davidson et al, 1996). In a study of piano prodigies, using historical data, Lehmann (1997) showed that all but one had been supervised in their practice during childhood. While this may be effective in improving performance it may have detrimental effects on intrinsic motivation (Lepper \& Greene, 1975; Lassiter, 1981) and its benefits may be fairly short term (Freeman, 1991). As children become older they need to become more independent in their practice. If practice is constantly supervised this is likely to lead to resentment and ultimately may be counter productive in that the child may give up playing (Sloboda and Davidson, 1996). The child's motivation needs to be internalised before the teenage years if they are to become committed to music.

While, the literature as a whole indicates that having a highly supportive and encouraging home background is important, it is clearly not essential. Highly effective individuals in a range of domains have been found to have histories marked by severe frustration, deprivation and traumatic experiences (MacKinnon, 1965). Musicians can achieve professional status with little practical support from the family, e.g. Louis Armstrong (Collier, 1983), the orphans at La Pieta in the time of Vivaldi (Howe, 1990). But such cases are rare. In these examples other aspects of the 
wider environment compensated for the lack of family support. Generally, families need to provide a minimal level of financial and practical help. Families may also have negative effects on motivation. Forcing children to practise, discouraging them from doing so, being excessively critical or demanding, having unrealistic expectations, or attempting to live out personal unfulfilled ambitions may all have deleterious effects on a child's motivation.

\section{The characteristics of the individual learner}

The model set out earlier suggests that musical motivation depends on a complex interaction between the characteristics of the individual and his or her environment. As we have seen, some environmental influences are internalised by the individual and come to affect the individual's functioning over time in a fairly consistent way. Where the environment satisfies individual needs and facilitates personal goals motivation is likely to be enhanced. Where the environment presents obstacles, the individual, depending on their own characteristics, may give up or be spurred on to greater efforts to overcome them, perhaps by finding a more conducive environment. In this section we will consider what we know about the individual characteristics that might influence musical motivation.

No clear relationship has been demonstrated between progress on an instrument and the appropriateness of the players' physical characteristics for that instrument (Lamp and Keys, 1935). However, some writers (Ben-Tovim and Boyd, 1990) have suggested that playing an instrument must be a physically rewarding experience. If the mismatch between physical characteristics and the requirements of the instrument is very great this may not be the case. 
Although no consistent picture of what constitutes the 'musical' personality has emerged from the research evidence to enhance our understanding of musical motivation considerable progress has been made through the work of Kemp (1996). Working within a trait framework, he showed that musicians tended to be more introverted than the rest of the population; that there were differences between players of different instruments; that the differences between male and female musicians tended to be less than in the general population; and that sensitivity and a tendency towards intuition emerged as stable traits in all groups regardless of age. Young musicians of secondary school age exhibited personality characteristics which reflected a pattern of good upbringing. They appeared to be the recipients of a type of nurturing that was encouraging and supportive leading to conscientiousness, controlled behaviour, which is socially acceptable and submissiveness. After entry into specialist music school, for the more talented students, these traits disappeared and were replaced by a lack of conscientiousness, a tendency to follow personal urges and assertiveness which combined to produce a syndrome of refusal to be bound by external pressures. What is not clear is whether the observed changes occurred because of actual changes in the personality of the young musicians as they progressed towards a career in music, or whether those who were less autonomous dropped out. Such evidence as there is tends to suggest the latter (Freeman, 1991). Kemp also found that those musicians who emerged as the most highly accomplished appeared to be self-motivated almost to the point of obsession, as if they were unable to separate their developing self-perception from that of being a musician. This suggests that what may be important in the long term is the commitment of the individual to music itself. This is reinforced by evidence that some children playing musical instruments experience bullying or loss of popularity as a result of their involvement with music (Howe and Sloboda, 1992). Nevertheless, they continue to play. 
Sloboda (1991) suggests that this commitment may depend on the experience of intense, aesthetic, emotional reactions to music, initially occurring in early childhood. Autobiographical accounts of the memories of emotional responses to music in childhood have shown that individuals with a lifelong commitment to music are likely to report strong emotions to music (Manturzewska, 1990; Sloboda, 1990). Those with no commitment to music often report negative emotions, frequently experienced where they had been strongly criticised by teachers. These had made them reluctant to become involved in musical activities and created anxiety. Positive emotional responses to music were most often experienced in non-threatening environments, e.g. the home, the concert hall, alone or with friends, where there were no performance expectations.

Approximately twice as many girls play instruments as boys (ABRSM, 1994). Girls also do better in school music examinations (DES, 1991). Why this should be so remains an unanswered question although it could be perceived as reflecting a societal view of music as a 'female' activity despite the proliferation of male role models in the profession. For girls and boys the main reason for wanting to play an instrument appears to be a personal desire to do so (MacKenzie, 1991), although social influences appear to be more important for girls, school factors for boys. Choice of instrument reflects stereotyping (Delzell and Leppla, 1992). Girls tend to prefer small high-pitched orchestral instruments. Boys tend to choose large low-pitched ones, although girls are less inhibited about selecting a masculine instrument, a tendency which is increasing, particularly in the younger age groups (Zervoudakes and Tanur, 1994). These stereotypical preferences can be manipulated indicating that they are learned (Abeles and Porter, 1978; Bruce and Kemp, 1993). 
As musicians develop through their careers, they progress through a number of stages (Sosniak, 1985; Harnischmacher; 1997). Manturzewska (1990), in a comprehensive analysis, identifies six stages across the life span of professional musicians. Each stage has different developmental tasks; serves different developmental functions; seems to be a "critical" period for learning specific skills; and has different motivational perspectives. The first two stages are important for educators. In the first stage, from birth to six years, the future musician seems to exhibit acousticmusical interests and preferences, enjoys being involved with music and may have an intense musical experience. In stage two, the need to play with music develops into a need to learn music. The learner begins to plead for or demand music lessons, sometimes overcoming severe obstacles to make this possible. As not all of the musicians studied came from musical backgrounds this suggests powerful internal motivating forces. Manturzewska suggests, supporting the model outlined earlier, that the characteristics of the individual, family surroundings and socio-cultural facilities have a 'co-creative function' in the development of musical interests, motivation and subsequently career.

Metacognitive strategies are concerned with the planning, monitoring and evaluation of learning and performance. The professional musicians' life is dominated by public performance and preparation for it. As practice is not always intrinsically motivating, developing strategies for managing motivation is crucial, although, extrinsic motivation in the form of public performance provides the necessary incentive for many musicians (Hallam, 1995; 1998b). Preparing for public performance necessitates giving priority to practice (Manturzewska, 1969), mobilizing arousal specifically for performance (Bochkaryov, 1975) and managing anxiety (Hamann, 1982) which may include adopting a range of life-style coping strategies (Bartel \& Thompson, 1994). These all depend on the development of appropriate metacognitive skills. Where these are insufficiently 
developed outstanding musicians may not make the most of their abilities (Manturzewska, 1990).

Novice musicians exhibit similar diversity in motivation to practise (intrinsic, extrinsic and mixed) as is found in professionals (Gellrich et al., 1986; Howe and Sloboda, 1991). Most students in Howe and Sloboda's (1991) sample required parental encouragement and support to practice and some exhibited very negative attitudes to practice which led to family tensions. Gellrich et al. (1986) identified three levels of achievement-related motives; a general achievement motivation; a specifically music oriented achievement orientation; and a sensualaesthetic motive, the pleasure and joy of playing certain pieces of music. Harnischmacher (1995) described how the development of long and short term goals, extrinsic and intrinsic, had positive effects on practice. These included wanting to play with others; playing particular favourite pieces of music; pleasing teachers and sometimes, but rarely, for love of the instrument. Constraints on practising were also itemised. These were environmental, unrelated to personal dispositions, and included, the interference of close relatives, dislike of particular music, the distractions of leisure activities and the weather.

The evidence about motivation to practise in both professional musicians and novices reinforces the complexity of musical motivation. It may be intrinsic or extrinsic, self-generated or supported by others. Different patterns of motivation may lead to similar learning outcomes. High levels of intrinsic motivation may lead to lengthy periods of practice for the sheer enjoyment of playing. Those motivated by external factors may adopt time effective practising strategies to optimise learning and reduce the amount of time spent in practice. Both may achieve similar levels of performance. Further research is required to explore the interplay between types of motivation, enjoyment, time spent practising, the effectiveness of practice and subsequent learning outcomes. 
Much recent motivational research, as we saw earlier, has centred on attribution theory, goal theory and self-efficacy. This has also been the case in music (for a review see Asmus, 1994). Chandler et al. (1988) found that music students who reported that they would choose to continue to play their instrument were more satisfied with their current level of performance; enjoyed playing more; believed that technical knowledge was an important influence on performance; practised more; expected to play the instrument longer; aspired to promotion within their musical group; generally attributed success to ability not luck; regarded personal effort as important; valued help from their teacher; and believed that it was valuable and important to play an instrument.

Considering the effect of attributing success or failure to the use of particular learning strategies, Vispoel and Austin (1993) found that students who explained their failure in relation to using poor learning strategies or to making insufficient effort anticipated improving their performance, effort and strategy use in the future. Where failure was explained by lack of effort students were likely to try harder in the future but not necessarily to improve their learning strategies. Where explanations were in terms of inadequate learning strategies individuals indicated that they would improve their learning strategies and try harder. Explaining failure in terms of the adoption of less than optimal learning strategies seemed to be effective in improving these and increasing effort. Emotional reactions to success and failure in music students were also explored. While anger, upset and guilt at failure or feedback about failure were likely to lead to positive responses for future work, this applied less when the responses were characterised by shame or embarrassment. For those engaged in individual instrumental tuition rather than class music responses to failure were stronger. This was particularly the case where pupils explained the 
failure in terms of their lack of ability. Children learning to play instruments seemed to have a more personal investment in music. They may have also been more accustomed to success and therefore being told they lacked ability may have been more ego threatening. While emotions like anger, upset or guilt might motivate a general music student, for students involved in instrumental music no such benefit was apparent. Emotional reactions to failure seemed to have a debilitating effect. Taken together these studies indicate the motivational importance of being successful and, where one is not, making appropriate attributions which serve to maintain high musical self-esteem.

For a full understanding of musical motivation, the study of drop-outs is crucial. Studies which concentrate exclusively on the successful provide no comparison control group. The evidence from studies which have included dropouts suggests that those ceasing to play tend to do less practice and have attained less (Sloboda et al., 1996; Hallam, 1998a). They tend to perceive themselves as less musically able, musically inadequate, receiving less family encouragement and feel that they have greater strengths in other recreational activities (Frakes, 1984). The time costs of playing an instrument are too great in relation to the rewards they receive (Hurley, 1995). Overall, no single explanatory factor emerges but several which include lower socio-economic status, lower ability to understand instructions, poor self-concept in relation to reading music, maths, reading achievement and general scholastic attainment. (Klinedinst, 1991; Hallam, 1998).

\section{Future directions}


The evidence presented above suggests that motivation to be involved in active music making is determined by complex interactions between the individual and the environment within which they find themselves. Some of the environmental effects, in particular those relating to early musical experiences, learning outcomes, self-efficacy and subsequently self-esteem are internalized by the individual in such a way that they become part of that individual's characteristics rendering it both impossible and pointless to disentangle them. Once internalized they impact on motivation to continue to be involved in music. Motivation is inextricably linked to a self-perception of being musically efficacious. It is beyond the scope of this article to address the question of whether this musical self-efficacy is related to prior learning or 'ability' but this is clearly an issue that requires empirical investigation. The individual's commitment to and involvement in music making can also affect their environment and the people in it. Families may make changes to support their musical offspring, friends may be influenced to participate in making music. The transaction is bi-directional. However, the nature of the music profession, which is relentless in its demands on performers throughout the entirety of their performing careers, makes it likely that only a strongly experienced commitment to music itself will be sufficient to sustain musical motivation throughout a career as a musician. This proposition requires empirical investigation as does the way in which aspiring musicians set goals and work towards them.

As we have seen much of the research concerned with musical motivation has focused on the family and to a lesser extent the teacher. There has been relatively little consideration of what motivates pupils to take up playing a particular instrument and continue with it, despite the sacrifices which need to be made to achieve professional levels of competence. In addition, the role of peers, the school environment and the wider community in sustaining motivation have 
been relatively little explored as have the reasons why pupils giving up playing when they demonstrate high levels of expertise and potential. There has been even less research examining the way that these interact together to generate or reduce enthusiasm for and commitment to music. These are important omissions in the literature which need to be addressed. Finally, an exploration of the reasons why mature adults begin or recommence playing an instrument when there are no external pressures or extrinsic rewards might elucidate what it is that is intrinsically motivating in music.

\section{References}

ABELES, H.F \& PORTER, S.Y. (1978) The sex-stereotyping of musical instruments, Journal of Research in Music Education, 26(2), pp. 65-75.

ADLER, A. (1927) The practice and theory of individual psychology (New York, Harcourt Brace)

ALLPORT, G.W. (1937) Personality: A psychological interpretation (New York, Holt)

AMES, C \& ARCHER, J. (1988) Achievement goals in the classroom: Students' learning strategies and motivational processes, Journal of Educational Psychology, 80, pp. 260-267.

ASMUS, E.P. (1994) Motivation in music teaching and learning, The Quarterly Journal of Music Teaching and Learning, 5(4), pp. 5-32. 
ASSOCIATED BOARD OF THE ROYAL SCHOOLS OF MUSIC (1997) Making music: The Associated Board Review of the teaching, learning and playing of musical instruments in the United Kingdom ( London: ABRSM).

ATKINSON, J. (1964) An introduction to motivation (New York, D. Van Nostrand)

BALDWIN, M.W. \& HOLMES, J.G. (1987) Salient private audiences and awareness of the self. Journal of Personality and Social Psychology, 52, pp. 1087-1098.

BANDURA, A. (1977) Self-efficacy: Toward a unifying theory of behavioural change. Psychological review, 84, pp.191-215.

BANDURA, A. (1982) Self-efficacy mechanism in human agency, American Psychologist, 37, pp. 122-147.

BANDURA, A. (1989) Self-regulation of motivation and action through internal standards and goal systems. In L.A. PERVIN (ed) Goal concepts in personality and social psychology (Hillsdale, NJ, Erlbaum)

BAR-TAL, D. (1978) Attributional analysis of achievement related behaviour. Review of Educational Research, 48, pp. 259-71.

BARTEL, L.R. \& THOMPSON, E.G. (1994). Coping with performance stress: A study of professional orchestral musicians in Canada. The Quarterly Journal of Music Teaching and 
Learning, 5(4), pp. 70-78.

BASTIAN, H.G. (1989) Leben fur Musik. Eine Biographie-Studie uber usikalische (Hoch)Begabungen (Mainz, Germany: Schott).

BEN-TOVIM, A. \& BOYD, D. (1990) The right instrument for your child (London: Victor Gollancz Ltd)

BERGLAS, S. \& JONES, E.E. (1978) Drug choice as a self-handicapping strategy in response to noncontingent success, Journal of Personality and Social Psychology, 36, pp. 405-417.

BIGGS, J.B. (1987a) Student approaches to learning and studying (Hawthorn, Vic: Australian Council for Educational Research)

BIGGS, J.B. (1987b) The study process questionnaire (SPQ): Manual (Hawthorn, Vic: Australian Council for Educational Research)

BOCHKARYOV, L.L. (1975). The psychological aspects of musicians' public performance. Voprosy Psikhologii, 21, pp. 68-79.

BRUCE, R. AND KEMP, A (1993) Sex stereotyping in children's preferences for musical instruments, British Journal of Music Education, 10, pp. 213-17.

BUSS, A. (1989) Temperaments as personality traits In G.A. KOHNSTAMM, J.E. BATES \& 
M.K. ROTHBART (Eds) Temperament in childhood (New York, Wiley)

CALDER, B.J. \& STRAW, B.M. (1975) Self-perception and intrinsic and extrinsic motivation, Journal of Personality and Social Psychology, 13, pp. 599-605.

CANTOR, N. \& KIHLSTROM, J.F. (1985) Social intelligence: the cognitive basis of personality In P. SHAVER (ed) Review of personality and social psychology (Vol 6) (Beverly Hills, CA, Sage)

CANTOR, N. \& KIHLSTROM, J.F. (1987) Personality and social intelligence (Englewood Cliffs, NJ, Erlbaum)

CANTOR, N. \& ZIRKEL, S. (1990) Personality, cognition and purposive behaviour, In L. PERVIN (ed) Handbook of personality: Theory and research (New York, Guilford Press)

CATTELL, R.B. (1957) Personality and motivation structure and measurement (New York, Academic Press)

CHANDLER, T.A., CHIARELLA, D., \& AURIA, C. (1988) Performance expectancy, success, satisfaction, and attributions as variables in band challenges, Journal of Research in Music Education, 35, pp. 249-258.

CLIFFORD, M.M. (1986) The comparative effects of strategy and effort attributions British Journal of Educational Psychology, 56, pp. 75-83. 
COLLIER, J.L. (1983) Louis Armstrong: an American Genius (Oxford: Oxford University Press).

CONNELL, J.P. (1985) A new multi-dimensional measure of children's perceptions of control, Child Development, 56, pp. 1018-1041.

COVINGTON, M. (1984) The motive for self-worth. In R. AMES \& C. AMES (eds) Research on motivation in education: Student motivation (New York, Academic Press)

CSIKSZENTMIHALYI, M (1990) Flow: the psychology of optimal experience (New York: Harper Row).

DANNER, R.W. \& LONKY, E. (1981) A cognitive development approach to the effects of rewards on intrinsic motivation, Child Development, 52, pp. 1043-1052.

DAVIDSON, J.W., HOWE, M.J.A., MOORE, D.G. AND SLOBODA, J.A. (1996) The role of family influences in the development of musical ability. British Journal of Developmental Psychology, 14, pp. 399-412.

DE CHARMS, R. (1968) Personal Causation: The internal affective determinants of behaviour. (New York: Academic Press).

DECI, E.L. (1971) Effects of externally mediated rewards on intrinsic motivation. Journal of 
Personality and Social Psychology, 18, pp. 105-15

DECI, E.L. \& RYAN, R.M. (1980) The empirical exploration of intrinsically motivated processes In L. BERKOWITZ (Ed) Advances in experimental social psychology (Vol 13) (New York, Academic Press)

DECI, E.L. \& RYAN, R.M. (1985) Intrinsic motivation and self determination in human behaviour (New York, Plenum)

DEPARTMENT OF EDUCATION AND SCIENCE(1991) Music for ages 5 to 14: Proposals of the Secretary of State for Education and Science and Secretary of State for Wales (London: HMSO).

DELZELL, J.K. \& LEPPLA, D. A. (1992) Gender association of musical instruments and preferences of fourth-grade students for selected instruments. Journal of Research in Music Education, 40, pp. 93-103.

DIENER, C.I. \& DWECK, C.S. (1978) An analysis of learned helplessness: Continuous changes in performance, strategy and achievement cognitions following failure, Journal of Personality and Social Psychology, 36, pp. 451-462.

DIENER, C.I. \& DWECK, C.S. (1980) An analysis of learned helplessness: (II) The processing of success, Journal of Personality and Social Psychology, 39, pp. 940-952. 
DWECK, C.S. (1975) The role of expectations and attributions in the alleviation of learned helplessness, Journal of Personality and Social Psychology, 31, pp. 674-685.

DWECK, C.S. (1999) Self-theories: Their role in motivation personality and development (Philadelphia, PA, Psychology Press)

DWECK, C.S. \& ELLIOTT, E. S. (1983) Achievement motivation. In P. Mussen and E.M. Hetherington (eds) Handbook of Child Psychology (New York, Wiley)

DWECK, C.S. \& LEGGETT, E.L. (1988) A social cognitive approach to motivation and personality, Psychological Review, 95(2), pp. 256-373.

ECCLES, J. (1983) Expectancies, values and academic behaviours. In J.T. SPENCE (ed) Achievement and achievement motives (San Fransisco, Freeman)

ELLIOT, A. J. (1997) Integrating the 'classic' and 'contemporary' approaches to achievement motivation: A hierarchical model of approach and avoidance achievement motivation. In M. L. MAEHR \& P.R. PINTRICH (eds) Advances in motivation and achievement, Vol 10. (Greenwich, CT, JAI Press)

ELLIOTT, A.J. \& CHURCH, M. (1997) A hierarchical model of approach and avoidance achievement motivation, Journal of Personality and Social Psychology, 72, pp. 218-232.

ELLIOTT, E.S. \& DWECK, C.S. (1988) Goals: An approach to motivation and achievement, 
Journal of Personality and Social Psychology, 54, pp. 5-12.

EMMONS, R.A. (1989) The personal striving approach to personality In L.A. PERVIN (ed) Goal concepts in personality and social psychology (Hillsdale, NJ, Erlbaum)

ENTWISLE, D.R. (1972) To dispel fantasies about fantasy based measures of achievement motivation, Psychological Bulletin, 77, pp. 377-391.

ENTWISTLE, N. (1988) Styles of learning and teaching (London, David Fulton Publishers)

ERIKSON, E.H. (1950) Childhood and society (New York, Norton)

ERIKSON, E.H. (1959) Identity and the life cycle (New York, International University Press)

EYSENCK, H (1982) Personality, genetics and behaviour. (New York, Praeger)

FEATHER, N. (Ed) (1982) Expectations and actions. Hillsdale, New Jersey: Erlbaum.

FRAKES, L. (1984) Differences in music achievement, academic achievement and attitude among participants, dropouts and non-participants in secondary school music (Phd, University of Iowa).

FREEMAN, J. (1991) Gifted children growing up. (London,Cassell). 
FREUD, S (1960) The ego and the id (New York, Norton)

FREUD, S. (1949) An outline of psychoanalysis (New York, Norton)

GELLRICH, M. OSTERWOLD, M. \& SCHULZ, J. (1986). Leistungsmotivation bei Kindern im Instumentalunterricht. Bericht uber eine erkundungsstudie. (Children's performance motivation in instrumental teaching) Musikpsychologie, 3, pp. 33-69.

GOOD, T. L. \& BROPHY, J.E. (1991) Educational Psychology, (New York, Longman)

HALLAM, S. (1995) Professional musicians' orientations to practice: implications for teaching. British Journal of Music Education, 12(1), pp. 3-19.

HALLAM, S. (1997) What do we know about practising? Towards a model synthesising the research literature. In Jorgensen, H., \& Lehman, A. (Eds) Does practice make perfect? Current theory and research on instrumental music practice (Oslo: NMH-publikasjoner 1997:1, Norges musikkh gskole).

HALLAM, S. (1998a) Predictors of achievement and drop out in instrumental tuition, Psychology of Music, 26(2), pp. 116-132.

HALLAM, S. (1998b) Instrumental Teaching: A practical guide to better teaching and learning. (Oxford, Heinemann) 
HALLAM, S. \& PRINCE, V. (2000) Research into Instrumental Music Services, Research Report RR229 (London, DfEE).

HAMANN, D.L. (1982). An assessment of anxiety in instrumental and vocal performances. Journal of Research in Music Education, 30, pp. 77-90.

HARNISCHMACHER, C. (1997) The effects of individual differences in motivation, volition, and maturational processes on practice behaviour of young instrumentalists. In Jorgensen, H., \& Lehman, A. (Eds) Does practice make perfect? Current theory and research on instrumental music practice. (Oslo: NMH-publikasjoner 1997:1, Norges musikkh gskole)

HARTER, S. (1981) A new self-report scale of intrinsic versus extrinsic orientation in the classroom: Motivational and informational components, Developmental Psychology, 17, 300312.

HARTER, S. (1985) Competence as a dimension of self-evaluation: Toward a comprehension model of self-worth, In R. LEAHY (ed) The development of the self (New York, Academic)

HAU, K.T. \& SALILI, F. (1990) Examination result attribution, expectancy and achievement goals amongst Chinese students in Hong Kong, Educational Studies, 16, pp.17-31.

HENDERSON, V., \& DWECK, C.S. (1990) Achievement and motivation in adolescence: A new model and data. In S. FELDMAN \& G. ELLIOTT (eds) At the threshold: the developing adolescent. (Cambridge, MA, Harvard University Press) 
HEPPER, P.G. (1988) Fetal 'soap’ addiction. Lancet, 1, pp. 1147-8.

HOLLOWAY, S.D. (1988) Concepts of ability and effort in Japan and the United States, Review of Educational Research, 58, pp. 327-43

HORNEY, K. (1950) Neurosis and human growth (New York, Norton)

HOWE, M.J.A. (1990) The origins of exceptional ability (Oxford, Blackwell).

HOWE, M.J.A., DAVIDSON, J.W., MOORE, D.M. \& SLOBODA, J.A. (1995) Are there early childhood signs of musical ability? Psychology of Music, 23, pp. 162-76.

HOWE, M.J.A. \& SLOBODA, J.A. (1991) Young musicians' accounts of significant influences in their early lives 1 . The family and the musical background. British Journal of music Education, 8, pp. 39-52.

HOWE, M.J.A. AND SLOBODA, J. (1992) Problems experienced by talented young musicians as a result of the failure of other children to value musical accomplishments. Gifted Education, 8 , pp. 16-18.

HULL, C.L. (1943) Principles of Behaviour (New York, Appleton-Century-Crofts)

HURLEY, C.G. (1995) Student motivations for beginning and continuing/discontinuing string 
music tuition. The Quarterly Journal of Music Teaching and Learning, 6(1), pp. 44-55.

JORGENSEN, H. (1997) Time for practising? Higher level music students' use of time for instrumental practising. In JORGENSEN, H., \& LEHMAN, A. (Eds) Does practice make perfect? Current theory and research on instrumental music practice (Oslo: NMH-publikasjoner 1997:1, Norges musikkh gskole).

KAGAN, J. \& SNIDMAN, N. (1991) Temperamental factors in human development. American Psychologist, 46, pp. 856-862

KELLY, G. A. (1955) The psychology of personal constructs (New York, Norton)

KEMP, A.E. (1996) The Musical Temperament: Psychology and Personality of Musicians (Oxford: Oxford University Press).

KLINEDINST, R.E. (1991) Predicting performance achievement and retention of fifth-grade instrumental students. Journal of Research in Music Education, 39(3), pp. 225-238.

KLINGER, E. (1975) Consequences of commitment to and disengagement from incentives, Psychological Review, 82(1) pp. 1-25

KLINGER, E. (1977) Meaning and void: Inner experience and the incentives in people's lives (Minneapolis, University of Minneapolis Press) 
KLINGER, E. (1987) Current concerns and disengagement from incentives In F. HALISCH \& J. KUHL (eds) Motivation, intention and volition (New York, Springer-Verlag)

KOESTNER, R. \& MCCLELLAND, D.C. Perspectives on competence motivation (1990) In L. PERVIN (ed) Handbook of personality: Theory and research (New York, Guilford Press)

LAMP, C. \& KEYS, N. (1935) Can aptitude for specific instruments be predicted? American Journal of Educational Psychology, 26, pp. 587-96.

LASSITER, D.G. (1981) A survey of parental involvement in the development of professional musicians. (Unpublished Masters Thesis, Florida State University, Tallahassee).

LEBLANC CORPORATION (1961). The influence of parents' attitudes on children's musical activity. (Kenosha, WI, Leblanc Corporation)

LECANUET, J.P. (1996) Prenatal auditory experience, In I. DELIEGE \& J.A. SLOBODA (eds) Musical Beginnings: Origins and development of musical competence, (Oxford, Oxford University Press).

LEHMANN, A.C. (1997) The acquisition of expertise in music: efficiency of deliberate practice as a moderating variable in accounting for sub-expert performance, In I. DELIEGE \& J. SLOBODA Perception and cognition of music (Hillsdale, NJ, Lawrence Erlbaum)

LEPPER, M. \& GREENE, D. (1975) Turning play into work: Effects of adult surveillance and 
extrinsic rewards on children's intrinsic motivation. Journal of Personality and Social Psychology, 31, pp. 479-86.

LEPPER, M., GREENE, D. \& NISBETT, R.I. (1973) Undermining childrens' intrinsic interest with extrinsic reward: A test of the 'over justification' hypothesis. Journal of Personality and Social Psychology, 28, pp. 129-37.

LEWIN, K. (1951) Intention, will and need. In D. RAPAPORT (ed) Organisation and pathology of thought (New York, Columbia University Press)

LICHT B.G. \& DWECK, C. S. (1984) Sex differences in achievement orientations: Consequences for academic choices and attainments In M. MARLAND (ed) Sexdifferentiation and schooling (London, Heinemann)

LITTLE, B.R. (1989) Personal projects analysis: Trivial pursuits, magnificent obsessions and the search for coherence in D.M. BUSS \& N. CANTOR (eds) Personality psychology: Recent trends and emerging directions (New York, Springer-Verlag)

MACKENZIE, C.G. (1991) Starting to learn to play a musical instrument: a study of boys and girls' motivational criteria, British Journal of Music Education, 8(1), pp. 15-20

MACKINNON, D.W. (1965) Personality and the realization of creative talent, American Psychologist, 20, pp. 273-281. 
MACRAE, R. R. \& COSTA, P. T. (1987). Validation of the five-factor model of personality across instruments and observers, Journal of Personality and Social Psychology, 52, pp. 81-90.

MAEHR, M.L. \& MIDGELY, C. (1996) Transforming school cultures (Boulder, CO, Westview Press)

MANTURZEWSKA, M. (1969). Psychologiczne Warunki Osiagniec Pianistycznych (Psychological conditions and piano achievement) (Wroclaw, Ossolineum).

MANTURZEWSKA. M. (1990). A biographical study of the life-span development of professional musicians, Psychology of Music, 18(2), pp. 112-139.

MARKUS, H. \& OYSERMAN, D. (1989) Gender and thought: The role of the self-concept. In M. CRAWFORD \& M. HAMILTON (eds) Gender and thought (New York, Springer-Verlag)

MARKUS, H. \& RUVOLO, A. (1989) Possible selves: Personalized representations of goals. In L.A. PERVIN (ed) Goal concepts in personality and social psychology. (Hillsdale, New Jersey: Lawrence Erlbaum Associates).

MARTON, F. \& SALJO, R. (1976) On qualitative differences in learning 1 - Outcome and process, British Journal of Educational Psychology, 46, pp. 4-11.

MASLOW, A.H. (1954) Motivation and Personality (New York, Harper) 
MCADAMS, D.P. (1988) Unity and purpose in human lives: The emergence of identity as a life story. In A.I. RABIN (ed) Studying persons and lives (New York, Springer Publishing Company)

MCCLELLAND, D.C., ATKINSON, J.W., CLARK, R.W., \& LOWELL, E.L. (1953) The achievement motive (New York, Appleton - Century- Crofts).

MEAD, G.H. (1934) Mind, self and society (Chicago, University of Chicago Press)

MISCHEL, W. (1973) Toward a cognitive social learning reconceptualisation of personality, Psychological Review, 80, pp. 252-283

MUELLER, C.M. \& DWECK, C.S. (1998) Intelligence praise can undermine motivation and performance, Journal of Personality and Social Psychology, 75, pp. 33-52.

MURRAY, H. A. (1938) Explorations in personality. (New York, Oxford University Press)

NICHOLLS, J. (1984) Achievement motivation: Conceptions of ability, subjective experiences, task choice and performance, Psychological Review, 92(3), pp. 328-346.

NOREM, J.K. \& CANTOR, N. (1986) Defensive pessimism: Harnessing anxiety as motivation, Journal of Personality and Social Psychology, 5(6), pp. 1208-1217.

PINTRICH, P.R. (1989) The dynamic interplay of student motivation and cognition in the college 
classroom, In M.L. MAEHR \& P.R. PINTRICH (eds ) Advances in Motivation and Achievement: Motivation Enhancing Environments (Vol 6) (Greenwich, CT, JAI Press Inc.)

PINTRICH, P.R. \& GARCIA, T. (1994) Self-regulated learning in college students: Knowledge, strategies and motivation. In P.R. PINTRICH, D.R. BROWN, C.E. WEINSTEIN (eds) Students' motivation, cognition and learning: Essays in honor of Wilbert J. McKeachie (Hillsdale, NJ, Erlbaum)

ROGERS, C.R. (1961) On becoming a person. (Boston, Houghton Mifflin)

ROTTER, J.B. (1966) Generalised expectancies for internal versus external control of reinforcement. Psychological monograph, 80.

RUBIN-RABSON, G. (1941a). Studies in the Psychology of Memorising Piano Music: IV. The effect of incentive. Journal of Educational Psychology, 32, pp. 45-54.

RYAN, R. M. (1982) Control and information in the intrapersonal sphere: An extension of cognitive evaluation theory, Journal of Personality and Social Psychology, 43, pp. 450-461.

SATT, B.J. (1984) An investigation into the acoustical induction of intra-uterine learning. (Unpublished D. Phil thesis. Californian School of Professional Psychologists).

SCHLENKER, B.R. \& WEIGOLD, M.F. (1989) Goals and the self-identification process: Constructing desired identities. In L.A. PERVIN Goal concepts in personality and social 
psychology (Hillsdale, NJ, Erlbaum)

SELIGMAN, M.E. \& MAIER, S.F. (1967) Failure to escape traumatic shock, Journal of Experimental Psychology, 74, pp. 1-9.

SELIGMAN, M.E. \& NOLEN-HOEKSEMA, S. (1987) Explanatory style and depression In D. MAGNUSSON \& A. OHMAN (eds) Psychopathology: An interactional perspective (Orlando, FL, Academic Press)

SERGEANT, D. (1969). Experimental investigation of absolute pitch. Journal of Research in Music Education, 17, pp. 135-43.

SKINNER, B.F. (1950) Are theories of learning necessary? Psychological Review, 57, pp. 193216.

SIMONTON, D.K. (1997) Products, persons, and periods: histrometric analyses of compositional creativity. In D.J. HARGREAVES \& A.C. NORTH, The Social Psychology of Music (Oxford, Oxford University Press).

SLOBODA, J.A. (1990) Music as a language. In F. WILSON, \& F. ROEHMANN (eds) Music and child development (St Louis, Missouri, MMB Inc).

SLOBODA, J.A. (1991). Musical expertise. In A. ERICSSON, \& J. SMITH (Eds) Toward a General Theory of Expertise: Prospects and Limits (Cambridge, Cambridge University Press). 
SLOBODA, J.A. \& DAVIDSON, J. (1996) The young performing musician In I. DELIEGE \& J.A. SLOBODA (eds) Musical Beginnings: Origins and development of musical competence (Oxford, Oxford University Press).

SLOBODA, J.A., DAVIDSON, J.W., HOWE, M.J.A. \& MOORE, D.G, (1996) The role of practice in the development of performing musicians. British Journal of Psychology, 87, pp. 287-309.

SLOBODA, J.A. \& HOWE, M.J.A. (1991) Biographical precursors of musical excellence: an interview study. Psychology of Music, 19, pp. 3-21.

SORICH, L. \& DWECK, C.S. (2000) Mastery oriented thinking. In C.R. Snyder (ed) Coping (New York, Oxford University Press)

SOSNIAK, L.A. (1985) Learning to be a concert pianist. In B.S. BLOOM (Ed) Developing talent in young people (New York: Ballentine)

SPENCE, K.W. (1942) Theoretical interpretations of learning. In F.A. MOSS (ed) Comparative Psychology (New York, Prentice-Hall)

STIPEK, D.J. \& GRALINSKI, H. (1996) Children's beliefs about intelligence and school performance, Journal of Educational Psychology, 88, pp. 397-407. 
SULLIVAN, H.S. (1964) The fusion of psychiatry and social science (New York, Norton)

THORNDIKE, E. L. (1913) Educational Psychology (Vols 1 and 2) (New York, Columbia University Press)

VALLACHER, R.R. \& WEGNER, D.M. (1987) What do people think they're doing? Action identification and human behaviour, Psychological Review, 94, pp. 3-15.

VISPOEL, W.P., \& AUSTIN, J.R. (1993) Constructive response to failure in music: The role of attribution feedback and classroom goal structure. British Journal of Educational Psychology, 63, pp. 110-129.

WAGNER, M.J. (1975). The effect of a practice report on practice time and musical performance. In C.K. MADSEN, R.D. GREER, \& C.H. MADSEN, JR., (Eds), Research in music behaviour (New York: Teachers College Press).

WEINER, B. (1986) An attributional theory of motivation and emotion (New York: SpringerVerlag).

WHITE, R.W. (1959) Motivation reconsidered: The concept of competence, Psychological Review, 66, pp. 297-333.

WOLFE, D.E. (1987). The use of behavioural contracts in music instruction. In C.K. MADSEN \& C.A. PRICKETT (Eds) Applications of research in music behaviour (Tuscaloosa, AL: 
University of Alabama Press).

ZDZINSKI, S.F. (1991). Relationships among parental involvement, music aptitude, and musical achievement of instrumental music students. Journal of Research in Music Education, 40(2), pp. 114-125.

ZERVOUDAKES, J. \& TANUR, J. (1994) Gender and musical instruments: Winds of change. Journal of Research in Music Education, 42, pp. 58-67. 